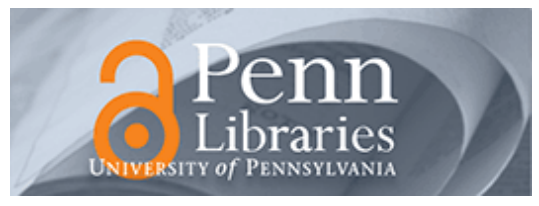

University of Pennsylvania ScholarlyCommons

Marketing Papers

Wharton Faculty Research

May 1970

\title{
An application of econometric models to international marketing
}

J. Scott Armstrong

University of Pennsylvania, armstrong@wharton.upenn.edu

Follow this and additional works at: https://repository.upenn.edu/marketing_papers

\section{Recommended Citation}

Armstrong, J. S. (1970). An application of econometric models to international marketing. Retrieved from https://repository.upenn.edu/marketing_papers/5

Postprint version. Published in Journal of Marketing Research, Volume 7, Issue 2, May 1970, pages 190-198. The author has asserted his/her right to include this material in ScholarlyCommons@Penn.

This paper is posted at ScholarlyCommons. https://repository.upenn.edu/marketing_papers/5

For more information, please contact repository@pobox.upenn.edu. 


\title{
An application of econometric models to international marketing
}

\author{
Abstract \\ Introduction: With more and more firms contemplating expansion in the international market, the question \\ of how a firm estimates its sales potential in a given country takes on increasing importance. Certainly \\ one vital piece of information in estimating sales potential would be the size of the total current market in \\ that country. This article considers the various ways in which firms might estimate market size by country, \\ with particular consideration given to the use of econometric models. \\ The article aims at three related questions. First, what has happened over the past thirty years in the use \\ of econometric models for measuring geographical markets? Second, is it possible to demonstrate that \\ currently available econometric techniques lead to "improved" measurement of geographical \\ markets-and, in particular, for international markets? Finally, have advances in applied econometric \\ analysis over the past thirty years led to any demonstrable progress in measuring geographical markets?

\section{Comments} \\ Postprint version. Published in Journal of Marketing Research, Volume 7, Issue 2, May 1970, pages \\ 190-198. The author has asserted his/her right to include this material in ScholarlyCommons@Penn.
}




\title{
An Application of Econometric Models to International Marketing
}

\author{
J. Scott Armstrong
}

Reprinted with permission from Journal of Marketing Research, VII (May 1970), 190-198

\section{Introduction}

With more and more firms contemplating expansion in the international market, the question of how a firm estimates its sales potential in a given country takes on increasing importance. Certainly one vital piece of information in estimating sales potential would be the size of the total current market in that country. This article considers the various ways in which firms might estimate market size by country, with particular consideration given to the use of econometric models.

The article aims at three related questions. First, what has happened over the past thirty years in the use of econometric models for measuring geographical markets? Second, is it possible to demonstrate that currently available econometric techniques lead to "improved" measurement of geographical markets—and, in particular, for international markets? Finally, have advances in applied econometric analysis over the past thirty years led to any demonstrable progress in measuring gem graphical markets?

\section{Methods For Measuring Sales Rates By Country}

\section{Trade and Production Data}

The most common approach to measuring sales rates by country is to use trade and production data, which appear to be improving rapidly in both quality and availability. The adoption of a uniform tariff classification system (the Brussels Nomenclature) by many countries has improved comparability of data among countries. This information is also relatively easy to procure, as the U.N. now publishes import-export data [22]. Still, as anyone who has worked: with international trade and production figures knows, the quality of the data leaves much to be desired [14].

A major problem with trade and production data is that they do not directly measure sales to final consumers. These lag trade and production data and changes in inventories also complicate measurement. One way to compensate for inventory and other short-term fluctuations is to utilize measurements based on longer time periods. In other words, the average sales rate over a six-year period would provide a more reliable estimate than the sales rate for a single year. This gain in reliability must be weighed against a loss of validity, since the objective is to measure the current sales rate-not the rate of a few years ago.

\section{Consumer Surveys}

A more direct approach to measuring sales rates is to utilize consumer surveys in each country. This approach is becoming feasible as literacy is rising around the world and as the capability to do survey research is becoming more widespread [13]. While surveys eliminate many of the problems found with trade and production data, it is not easy to ensure that survey data are comparable across countries. Also, the survey method: depends upon the respondent's ability to remember what he purchased and when. The most serious drawback, however, is the cost of the survey.

\section{Econometric Models}

The econometric model attempts to measure sales indirectly by relating sales to the factors which cause them. This approach may prove to be much less expensive than the survey method mentioned above if data on the 
causal factors are not expensive to obtain. The forerunner of this approach, the use of regression models, was advocated in the 1930's as a means of estimating geographical market potentials [5, 6, 9, 24, 25].

The key difference between the econometric approach presented here and the approach advocated in the 1930 's is in the amount of a priori specification. The econometric approach calls for as detailed an a priori specification as possible whereas the earlier approach seemed to call for as little as possible.

What should be included in the a priori specification? Certainly it would seem that a priori reasoning should be used to guide the selection of causal variables. The objectives are to include all important variables, while restricting the number of variables to a manageable size. What is manageable depends on one's a priori knowledge and on the measurement model. For example, one may be very willing to impose an a priori estimate upon the relationship between sales and number of potential buyers (e.g., a per capita transformation). But where there is little a priori information on the effects of variables and where the regression model is used for measuring these relationships, it is generally true that only a small number of variables may be included. Ball [3] refers to a rule of thumb that there should be ten observations for each variable included in a regression model.

Current practice also calls for the researcher to specify the direction or sign of the relationship. In many cases he also makes an a priori specification of the functional relationship (e.g., additive or multiplicative) although many researchers prefer to experiment with different forms [16]. Finally, while a few researchers have been willing to specify the magnitude or ranges of values for the causal relationship [18], a priori specification is still controversial. The exception, of course, is researchers' willingness to place a priori estimates on measures of size, as in the per capita transformation, which puts an a priori value of 1.0 on the population elasticity of demand.

The literature from the 1930's seemed to want to avoid the subjective judgments required for a priori specification. In short, this approach was a non-theoretical use of regression analysis, such as that used in Hummel's summary of the Rayco Seat Cover Company study [11], where 300 variables "explained" variations in automobile seat cover sales per square mile. Simple plots of each variable against the sales measure for 150 sales offices eliminated 226 variables which appeared to be unrelated to sales. A stepwise regression then reduced the list of 74 variables down to the best 37 . This model was shown to produce an excellent fit to the data, but there was no evaluation of its usefulness in a predictive situation.

The current econometric approach, then, represents an extension of the regression work begun over 30 years ago. It recognizes the value of a priori knowledge and, in its ultimate form, would call for a complete specification of the model on a priori grounds. Measurement models (such as regression models) would be used to update the various parameters of the model.

\section{The Use of Different Approaches}

Each of the three approaches — trade and production data, surveys, and econometric models—has its own advantages and disadvantages. While the remainder of the article will concentrate on the econometric model, this is not to imply that it's the "best" approach. It would seem useful to utilize information from a number of approaches rather than just the "best." Thus, it might be possible to combine the sales estimates from the trade and product on data, from a consumer survey, and from an econometric model to yield a single estimate.

\section{Developing An Econometric Model: A Case Study}

Whether the econometric model provides a useful way to measure industry sales by country is obviously an empirical question. Data on the international market for still camera sales were used to examine whether the econometric model is useful in at least one real-world situation.

The econometric model was based on the following conceptual model:

$$
S_{i, t}=f\left(M_{i, t} ; A_{i, t} ; N_{i, t}\right)
$$


where:

$$
\begin{aligned}
& S=\text { camera sales per year by country } \\
& M=\text { market size (i.e., number of potential buyers) } \\
& A=\text { ability to buy } \\
& N=\text { consumer needs and } i \text { refers to the country and to the year. }
\end{aligned}
$$

It was then necessary to specify this model in operational terms.

\section{The Dependent Variable}

Initially, the only available operational measure for sales was the estimate for each country from trade and production data. Unit still camera sales from 1960-65 were estimated for 30 countries as being equal to imports plus production minus exports. $1^{1}$ Where possible, imports into country X from country $\mathrm{Y}$ (as reported by country $\mathrm{X}$ ) were averaged with exports from country $Y$ to country X (as reported by country Y). Theoretically, of course, there is no reason for these figures to differ, although they often differ substantially, reinforcing the comments made earlier about the poor quality of trade and production data. Here is one admittedly extreme example: Japan claimed 160,180 still cameras exported to the U.S. in 1956; the U.S. claimed 819,372 imported from Japan.

Table 1 summarizes the total sales of still cameras by country as estimated by trade and production data. These data required substantial subjective interpretation to make them comparable across countries.

\section{The Independent Variables}

Initially, there was a rather large number of potentially important operational variables. "Large)' is interpreted here relative to the number of independent observations (i.e., the number of countries) in the sample. An a priori analysis helped to reduce this set of variables to a manageable number. The following questions provided a guide:

1 Is the variable expected to be important to the camera purchase decision? (e.g., is the camera's price expected to affect the consumer's decision?)

2 Is there good a priori knowledge about the relationship implied in above? (e.g., do previous studies of "similar goods" provide any idea of the price elasticity.)

3 Does the variable show substantial fluctuation among countries? (e.g., does the price of cameras vary among countries?)

4 Are the data for this variable free from substantial measurement error? (e.g., is it possible to obtain useful data on camera price by country?)

While these criteria are rather loosely stated, they were easy to apply. The ratings indicated large differences among the variables with respect to importance. Repeated ratings of the variables at different times and various weighting schemes for the criteria led to similar results.

\footnotetext{
${ }^{1}$ For one country, Japan, an adjustment was also made for a large change in inventories over the time
} period. Inventory changes were assumed to be negligible for the other countries. 
Table 1

UNIT CAMERA SALES BY COUNTRY IN HUNDREDS (TRADE \& PRODUCTION DATA)

\begin{tabular}{|c|c|c|c|c|c|c|c|c|c|}
\hline Country & 1965 & 1964 & 1963 & 1962 & $196 t$ & 1960 & 1955 & 1954 & 1953 \\
\hline Austria & 780 & 1,010 & 770 & 840 & 730 & 910 & 106 & 880 & 257 \\
\hline Belgium-Luxemburz & 2,550 & 2,340 & 2,390 & 1,190 & 1,050 & $t, 110$ & 1.125 & 620 & 1,070 \\
\hline Denmark & 1,100 & 1,370 & 1,390 & 1,230 & 1,250 & 1,320 & 982 & 1,190 & 757 \\
\hline Finlend & 500 & 440 & 390 & 350 & 280 & 260 & 535 & 110 & 51 \\
\hline France & 14,670 & 13,460 & 11,340 & 10,400 & 8,990 & 8,800 & - & - & - \\
\hline W. Germany & 25,550 & 22,720 & 13,730 & 10,460 & 16,530 & 12,436 & - & 13,200 & - \\
\hline Ireland & 100 & 110 & 90 & 260 & 230 & 260 & - & 170 & - \\
\hline Italy & 7,840 & 7,370 & 6,070 & 3,110 & 2,880 & 3,500 & - & - & - \\
\hline Netherlands & 3,620 & 4,270 & 2,960 & 2,630 & 2,300 & 2,300 & 1,283 & 1,120 & 712 \\
\hline Norway & 710 & 430 & 350 & 540 & 510 & 510 & 593 & 390 & 555 \\
\hline Portugal & 290 & 460 & 110 & 190 & 260 & 210 & 152 & 290 & 138 \\
\hline Sweden & 3,770 & 3,900 & 2,700 & 2,300 & 2,000 & 2,000 & 1,300 & 1,800 & 940 \\
\hline Switzerland & 2,830 & 3,210 & 3,620 & 2,500 & 1,910 & 1,750 & 1,210 & - & 670 \\
\hline U. Kingdom & 15,620 & 21,430 & 17,040 & 15,840 & 16,230 & 16,800 & - & - & - \\
\hline Canada & 5,000 & 4,600 & 4,500 & 4,000 & 3,500 & 4,500 & - & - & $\rightarrow$ \\
\hline U.S. & 114,480 & 88,140 & 72,020 & 62,590 & 58,450 & 54,660 & - & - & - \\
\hline Argentina & 920 & 490 & 543 & 548 & 435 & 435 & - & - & - \\
\hline Brazil & 200 & 290 & 560 & 580 & 440 & 380 & - & - & - \\
\hline Guatemals & 20 & 20 & 20 & - & 20 & 50 & - & 40 & - \\
\hline Mexico & 600 & 730 & 760 & - & 670 & 600 & 195 & 750 & 173 \\
\hline Peru & 190 & 330 & 240 & 140 & 120 & 60 & 98 & 30 & 77 \\
\hline Venezuela & 610 & 460 & 520 & 220 & 360 & 400 & 131 & 70 & 199 \\
\hline Australia & 4,970 & 5,410 & 3,100 & 3,170 & 2,810 & 4,730 & - & - & - \\
\hline N. Zealand & 420 & 760 & 870 & 1,000 & 570 & 360 & 534 & 270 & 226 \\
\hline Japan & 17,500 & 26,620 & 21,950 & 15,100 & 10,150 & 10,290 & - & $\ldots$ & - \\
\hline Thailand & 180 & 180 & 130 & 110 & 99 & 85 & 72 & 23 & 57 \\
\hline Iraq & 50 & 40 & 30 & 40 & 50 & 110 & $\ldots$ & 40 & - \\
\hline Israel & 250 & 200 & 110 & 90 & 70 & 60 & 89 & 10 & $2 \mid$ \\
\hline S. Africa & 650 & 1,190 & 820 & 700 & 780 & 1,210 & 300 & 310 & 390 \\
\hline Yugoslavia & 530 & $\$ 20$ & 710 & 350 & 470 & 380 & - & 340 & - \\
\hline Totals & 226,590 & 212,480 & 169,833 & 140,698 & 134,144 & 130,470 & & & \\
\hline
\end{tabular}

Notes: Data from U. S. Dept. of Commerce, except: (1) Blanks indicate no information, (2) U. S. cstimates from Photo Dealer Annual Statistical Report. Adjustments of $+10 \%$ for 1960,1961 and 1962 were made to include cameras under $\$ 5.00$; (3) Japant estimates are from the Japanese Ministry of Trade and Industry (M1TJ). Supporting evidence from Far Eastern Ecanomic Review used to adjust the data for inventory ehanges (200,000 units per year reduetion) and for inclusion of lenses only in MITI figures ( $5.7 \%$ reduction).

Table 2 presents a summary of those variables which were selected for the analysis. Descriptions of each variable and data sources are also presented.

\section{Causal Relationships}

The next step of the a priori analysis was to decide on a functional form for the causal model. ${ }^{2}$ The concern of this study was to predict the relative scale of industry sales in each country. In other words, percentage errors were minimized by use of a multiplicative or "log-log" model. The basic assumption of constant elasticities (i.e., a one percent change in $\mathrm{X}$ causes a given percentage change in $\mathrm{Y}$ over all levels of $\mathrm{X}$ ) appeared to be a good representation of the causal relationships in this study. The multiplicative (or log-log) model has the additional advantage of facilitating use of results from previous studies for comparison with results from the current study, since one does not have to be concerned about the units of measurement. All results are unit-free and relate only to percentage changes.

There was no problem in specifying the direction or sign of each relationship. Indeed, the criteria for selection of variables above led to elimination of any potential variable if the a priori knowledge was so poor that the direction of the relationship could not be predicted.

2 Johnston [10, 12, pp. 44-52] and Prais and Houthakker [16, pp. 79-88] provide excellent discussions on the choice of functional forms. 
Table 2

1960-1965 DATA ON FACTORS CAUSING VARIATION IN CAMERA SALES AMONG COUNTRIES

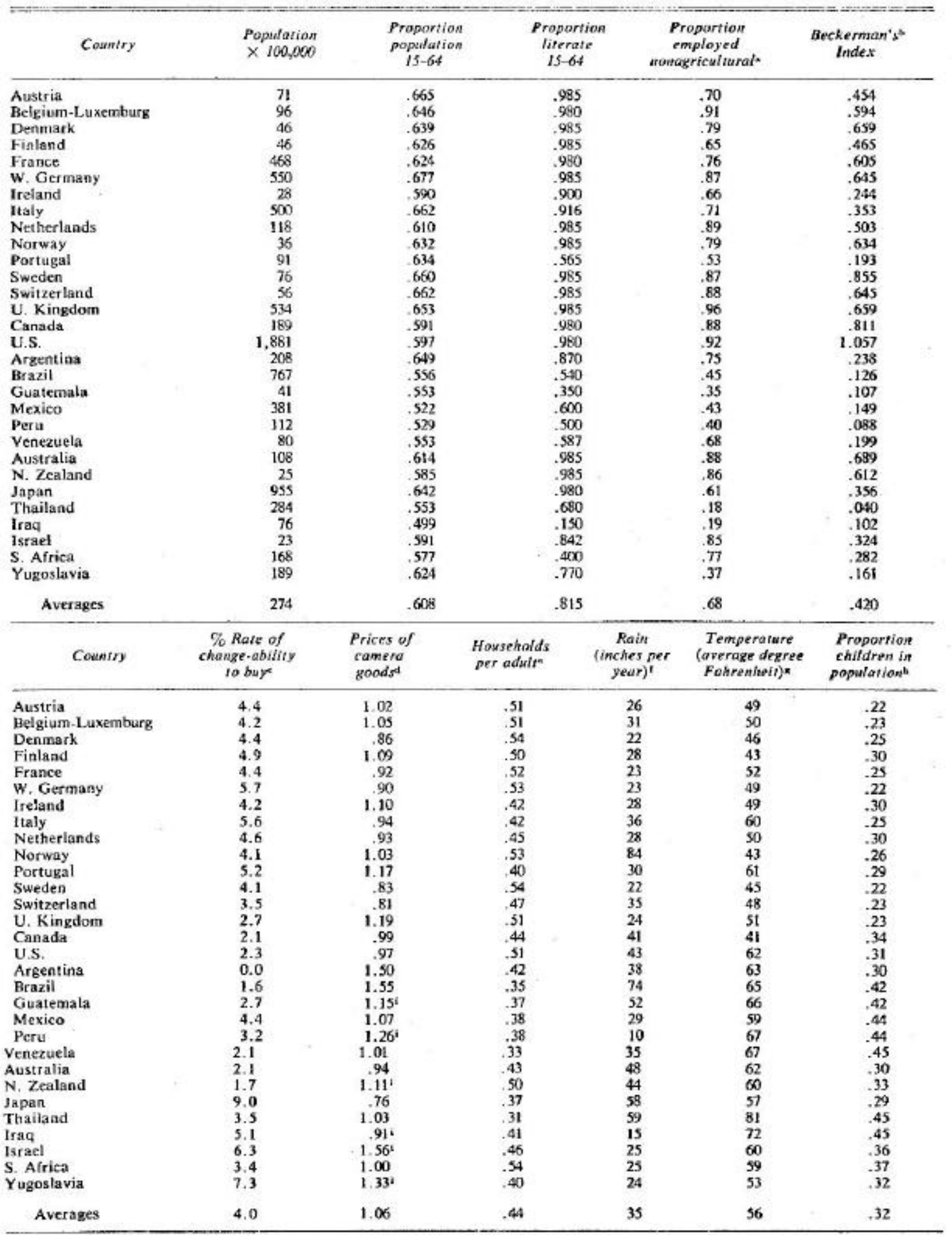


${ }^{a}$ Data in the first four columns are from [17, Tables 1, 2, and 64 respectively]. Column two data are from mid-1961; the rest are adjusted to represent the end of 1962.

b "Beckerman's Index of the standard of living" is based on a regression of private consumption in dollars versus steel consumption, cement production, domestic letters sent, stock of radio receivers, stock of telephones, stock of road vehicles, and meat consumption. The "predicted" values for each country were used as the standard of living measures 14 , Table 51, and are adjusted to represent the end of 1962.

${ }^{c}$ Obtained by averaging rate of change in PCE per capita, 1960-64 [7] and rate of change in per capita product at constant prices 1960-64 [20: 1967]. The latter data are given in constant prices while the former are adjusted by the 1960-64 cost of living index [8].

${ }^{\mathrm{d}}$ Data, obtained from a survey of importers, were adjusted to represent the end of 1962 by analysis of effects of changes in tariffs and taxes in each country [1].

e "Index of buying units" was based on number of households per adult [20: 1965]. Number of adults was estimated from the data above (total population times proportion of population between 15 and 64).

${ }^{\mathrm{f}}$ See [23].

${ }^{\mathrm{g}}$ See [8].

${ }^{\mathrm{h}}$ Estimated by using data on percentage on population under 15 in [19] and [20: 1963, 1965].

${ }^{i}$ Estimates were obtained from a model which estimated price on the basis of knowledge about tariffs, taxes, proportion imports, quotas and resale price maintenance.

Finally, the magnitude and range of the causal relationship (the elasticity) between still camera sales and each of the causal variables was specified Previously published demand studies for durable goods proved useful here. For example, income elasticities from most consumer durable goods studies tended to fall between +1.0 and +2.0 with an expected value around $t 1.3$.

It was possible to specify each component of the econometric model on a priori grounds except for the constant term. A priori analysis is a rather subjective and untidy business. It does, however, provide a means for utilizing knowledge built up through previous research and experience.

\section{Updating the Parameter Estimates}

Nineteen countries were selected from the 30 countries in Table 2 by a stratified sampling plan. These were then used in a regression model to obtain estimates for some of the model parameters, and the remaining 11countries were set aside to be used in the evaluation phase of the study.

After examining the results, the model was revised for what appeared to be errors in certain observations, and consideration was given to various combinations of causal variables. The net result of these manipulations was that the use of tests of statistical significance on these data was questionable; the objective at this stage was to measure relationships, of course, and testing of statistical significance was not necessary. In short, the philosophy here is that "anything goes" in measurement as long as the approach is disclosed and one does not need to perform statistical testing on the same data.

The figure summarizes the model developed from the regression across 19 countries. Its coefficients were based on the combination of the regression estimates and on the a priori estimates. Durbin [10] presented the classical procedure for combining different estimates in which each estimate is weighted inversely by its variance. His procedure assumes that the estimates are unbiased. Such an assumption did not seem realistic in this situation.

Where bias is likely to occur, one would prefer to weight by the mean square error. While much work has been carried out in recent years on the development of Bayesian regression analysis, an operational program could not be obtained at the time of the study. Instead, a heuristic procedure was used to combine the estimates. Each estimate was weighted inversely by its standard error-a less severe scheme than using variances. Estimates for the coefficient of least importance in the model were first combined. The effects of this variable were then removed from the data, after which the regression was re-estimated. Estimates for the least important remaining variable were then combined; the effects of this variable were removed; the regression was re-estimated, etc. This procedure was simply one of many operational schemes which might have been used in the absence of a Bayesian regression program. 
The figure indicates data from eleven variables used to explain variations in sales across countries. Population, standard of living, and price appeared to be the most important variables, although the additional eight variables also seemed worth including. The effect of four of the variables (those affecting market size) were specified completely on an a priori basis and estimates of some of the other seven variables were modified by a priori knowledge. This procedure was necessary, since the data could not provide estimates for seven coefficients with only 19 observations.

Details of this analysis are not presented here; see [1] for details of model development. Of course different researchers would come up with different models since their a priori knowledge would seldom agree. This is not a crucial element in this study. The point is that by following this general procedure one could develop a useful model. Sensitivity tests indicated that the predictions made in this paper were not highly dependent on variations in the a priori estimates as long as these variations were in the general region of values actually used. The a priori knowledge of most researchers would probably lead them to estimates within this general region.

ECONOMETRIC MODEL TO PREDICT CAMERA SALES BY COUNTRY

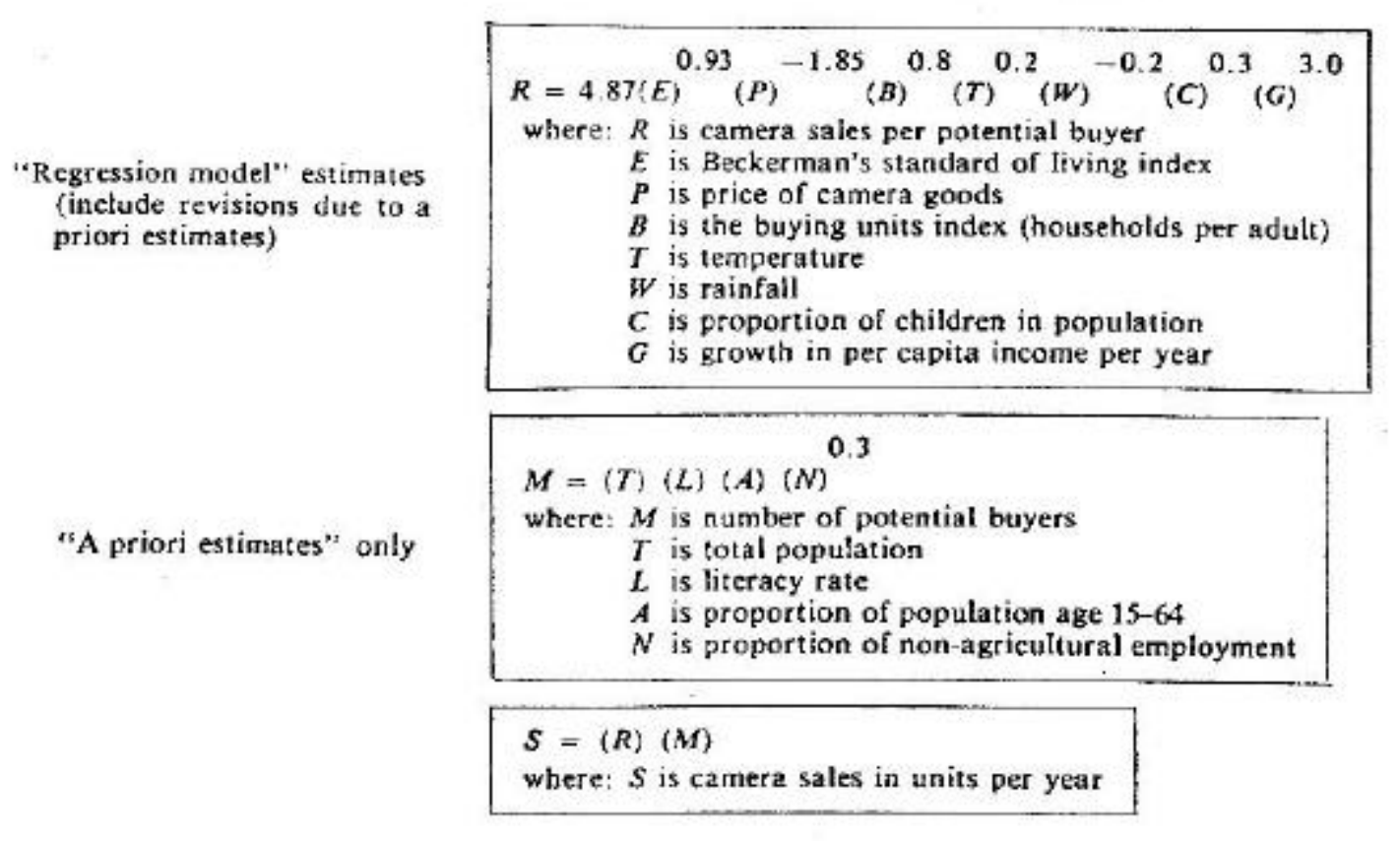

Evaluating The Econometric Model

\section{Explaining Variations in the Analysis Sample}

The model from the figure provided an excellent fit to the analysis sample. The $R^{2}$ between sales as measured by trade and production data and sales as predicted by the econometric model was over $99 \%$. However, the "experimentation" in fitting a regression model led to spuriously high measures of $\mathrm{R}^{2}$, so that measures of the fit to the analysis sample did not provide a good way of evaluating this model.

\section{Explaining Variations in the Validation Sample}

Eleven countries had been retained from the original 30 countries for a test of predictive validity. How well can camera sales be predicted in a country given only data about the causal variables? Table 3 presents the results of this analysis and indicates that the predictions of this model differ from the estimates derived from trade and production figures with a mean absolute percentage deviation of $31 \%$. Whether this is good depends, of course, on what decisions are to be made from the estimates and whether other models might provide an even closer fit. 
Table 3

Use of Econometric Model to Predict Sales for "Validation" Sample

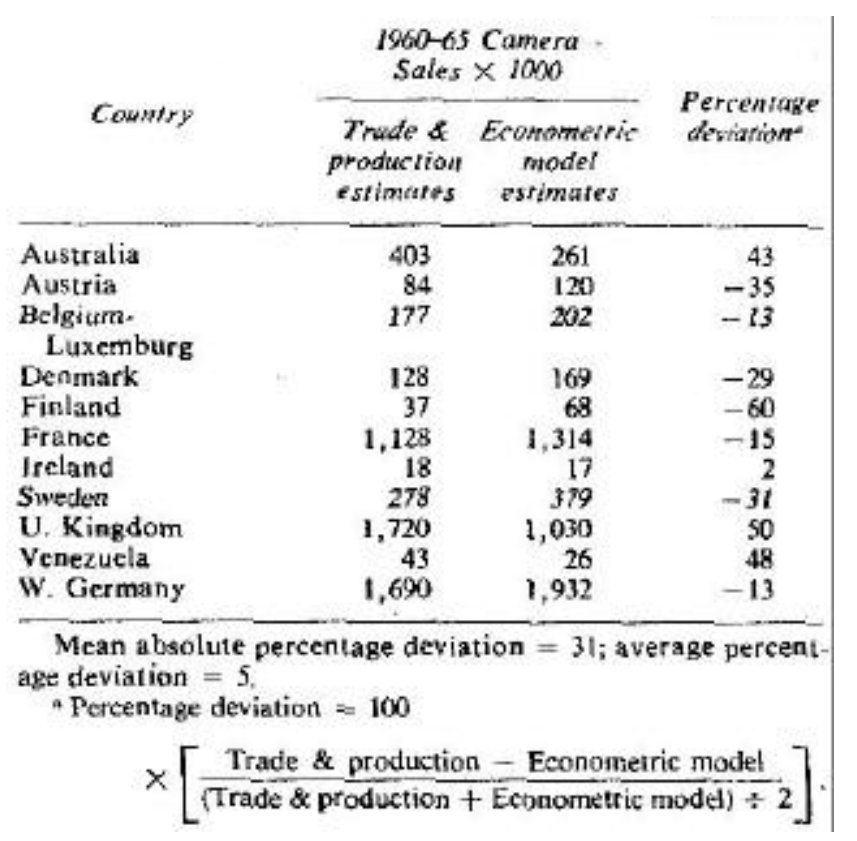

\section{A Test of Predictive Value}

Does the econometric approach help in the measurement of sales? Would this gain in measurement improve the ability to predict in a practical situation?

One situation in which improved measurement of current sales is of some importance is in sales forecasting. Traditionally, most of the emphasis in sales forecasting has been devoted to estimating the change in sales; the possibility that the estimates of current sales may be in error has not received much consideration. Zarnowitz [26], however, points out how errors in estimating current GNP are responsible for about $20 \%$ of the errors in predicting GNP one year ahead.

The question studied was whether information from the econometric model gave a better sales forecast than that based only on trade and production data. The "forecasting" situation examined really involved "backcasting" camera sales for 17 countries from 1953-55 on the basis of data from 1960-65 only. It was assumed that nothing was known before 1960 in obtaining these unconditional backcasts.

Two models were developed. One used an estimate of 1960-65 sales derived from trade and production data only (t.p.d.), while the other used t.p.d. and the 1960-65 econometric model predictions (e.m.p.) for each country. Each model used the same measure of change from 1960-65 to 1953-55 so that the change estimates represented a constant for the analysis. Details on the development of the model to predict change in sales are in [2].

The hypothesis tested was that a combined measure of 1960-65 sales (based on a weighted average of t.p.d. and of e.m.p.) would be superior to a measure based on t.p.d. only in predicting 1953-55 sales. The only available estimates of 1953-55 sales were, in fact, based only on t.p.d. This seems to represent a strong test of the hypothesis since measurement errors in t.p.d. (such as from definitional problems, cheating, or mistakes) would probably tend to be positively correlated over time.

To restate this problem, if measurement errors in t.p.d., the difference between t.p.d. and "true" values, were perfectly correlated over time, then current t.p.d. would provide a better prediction of t.p.d. for other time periods than would the e.m.p. To the extent that the errors are not correlated over time, it is possible that the 
econometric model wilt contribute to prediction of t.p.d. The hypothesis assumes that errors in t.p.d. are not perfectly correlated over time.

An a priori weighting scheme was used which represented the researcher's degree of confidence in each estimate of the current sales rate. The t.p.d. (from Table 1) were weighted twice as heavily as the e.m.p. (from the model presented in the figure; updating this model by including all 30 countries of Table 1 in the regression led to only minor changes in the e.m.p.).

Results of the backcasting test are presented in Table 4. The use of the e.m.p. led to a reduction in mean absolute percentage error from $30 \%$ to $23 \%$, an improvement which would appear to be of substantial importance for decisions utilizing these predictions. Here is one situation, then, in which the e.m.p added useful information.

The backcast error was reduced for 14 of the 17 countries. The sign test at the .05 level of statistical significance was used to test the null hypothesis that there was no improvement from using the e.m.p. The null hypothesis (calculated level of significance $=.01$ ) was rejected.

In testing the sensitivity of the results to the a priori weighting scheme, it was found that any scheme giving some weight to e.m p. resulted in improved forecasts. The optimal scheme weighted the e.m.p. about twice as heavily as the t.p.d., yielding a mean absolute percentage error of $21 \%$. If only the e.m.p. were used, the mean absolute percentage error was $23 \%$.

The success of the e.m.p. does not, of course, demonstrate that the particular econometric model developed here is the "best" which could be developed. Alternative formulations of the model tended to produce similar predictions of sales in each country, however, again leading to the conclusion that the results are not extremely sensitive to the researcher's a priori knowledge.

\section{Other Support For the Econometric Model}

The use of the econometric model for improved forecasts over time represents only one of a number of potential uses, including:

1. The econometric model across countries estimates parameters (e.g., price and income elasticities) for developing a model to predict changes in sales over time.

2. In cases where no recent historical sales data are available (e.g., due to government prohibitions on sales) or where the market has been severely restricted by the government, the econometric model estimates what sales would be if government restrictions were removed. This approach requires that a model also be developed to predict prices in these countries.

3. The e.m.p. may be used for "control" purposes following the philosophy of quality control charts. Thus, when sales as measured by t.p.d. (or by survey data in a country are much lower than predicted by the model, a further examination may show that the market has not been fully exploited because of a weak marketing effort. In certain countries, high sales may be caused by certain aspects of the marketing program.

\section{The Value Of The A Priori Analysis}

While it was difficult to generalize from this one situation what particular aspects of a priori analysis are of greatest importance, an evaluation can be made of the overall value of the a priori analysis. An alternative econometric model was developed which utilized very little a priori knowledge. This model was designed to match the accepted "non-theoretical" procedure advocated in the 1930's. Fifteen "reasonable" variables bearing a possible relationship to camera sales per capita in each country were selected. A stepwise regression model was then used to develop the model with the highest adjusted $R^{2}$.

The fit to the analysis sample was good - better, as expected, than the model using the a priori information. When this model was tested against the validation sample, however, the mean absolute deviation from trade and 
production estimates was 52\%, against the mean absolute deviation of $31 \%$ for the model using a priori information. These differences are significant at the .05 level.

Table 4

UNCONDITIONAL. BACKCASTS OF 1954 CAMERA

SALES/YEAR BASED ON DIFFERENT ESTIMATES

OF 1960-65 SALES (PERCENTAGE DEVIATIONS

(N PARENTHESES*)

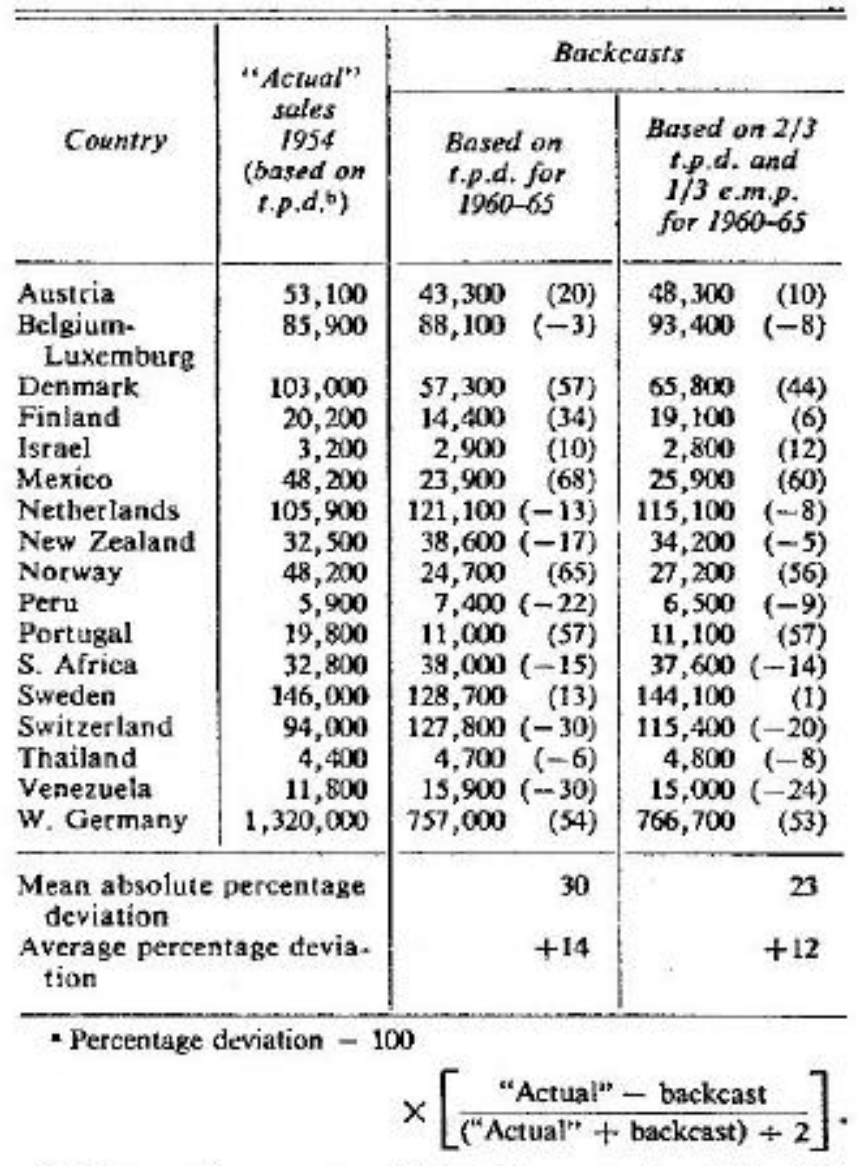

- These estimates were obtained by averaging 1953, 1954 and 1955 data. The 1954 data were weighted twice as heavily as the 1953 and 1955 data.

\section{Summary}

This article has discussed changes in the past thirty years in the use of econometric models for measuring geographical markets. The major advance was found in the recent emphasis on use of a priori information.

The results for a particular case, the international market for still cameras, indicated that econometric models, at their current level of development, provide useful information for estimating international markets. A test in which the use of the additional information from the econometric model led to improvement in backcasting showed that the mean absolute percentage error for an 8-year backcast was reduced from $30 \%$ to $23 \%$. The model has other benefits beside its improved predictions over time. An examination of the value of a priori analysis showed a reduction of mean absolute percentage error for predictions of the 1960-65 market sizes of 11"new" countries from $52 \%$ to $31 \%$. 


\section{References}

1. J. Scott Armstrong, "Long-Range Forecasting for a Consumer Durable in an International Market," unpublished Doctoral dissertation, Sloan School, Massachusetts Institute of Technology, 1968.

2. _ - "Long-Range Forecasting for International Markets. The Use of Causal Models," Proceedings, Fall Conference, American Marketing Association, 1968.

3. G. H. Ball, "Data Analysis in the Social Sciences: What about the Details?" Proceedings, Fall Joint Computer Conference, Las Vegas, Nevada 1965, 533-59.

4. Wilfred, Beckerman, International Comparisons of Real Incomes, Paris: Organization for Economic Cooperation and Development, 1966.

5. L. O. Brown, "Quantitative Market Analysis-Multiple Correlation: Accuracy of the Methods," Harvard Business Review, 16 (Autumn 1937), 62-73.

6. _- "Quantitative Market Analysis-Scope and Uses," Harvard Business Review, 15 (Spring 1937), 233-4.

7. Business International Corporation, Business International, New York, December 1966.

8. Copley International Corporation, The Gallatin Statistical Annual, New York, 1966.

9. Donald R. G. Cowan, "Sales Analysis From the Management Standpoint" Journal of Business, 9 (January, April, July, October 1936), and 10 January 1937).

10. J. Durbin, '4A Note on Regression When There is Extraneous Information About One of the Coefficients ' Journal of the American Statistical Association, 48 (September 1953), 799-808.

11. F. E. Hummel, Market and Sales Potential, New York: Ronald Press Co., 1961.

12. J. Johnston, Econometric Methods, New York: McGraw Hill, 1963.

13. D. V. McGranahan, "Comparative Social Research in the United Nations," in R. L Merritt and S. Rokkan, eds., Comparing Nations, New Haven: Yale University Press. 1966.

14. Oskar Morganstern, On the Accuracy of Economic Observations, Princeton: Princeton University Press, 1963.

15. Reed Moyer, "International Market Analysis," Journal of Marketing Research, 5 (August 1968), 353-60.

16. S. J. Prais and H. S. Houthakker, The Analysis of Family Budgets, Cambridge, Cambridge University Press, 1955.

17. B. M. Russett, et al., eds., World Handbook of Political and Social Indicators, New Haven: Yale University Press, 1964.

18. H. Theil and A. S. Goldberger, "On Pure and Mixed Statistical Estimation in Economics," International Economic Review, 2 (1961), 65-8.

19. United Nations, Demographic Yearbook, New York, 1964.

20. —, Statistical Yearbook, New York, 1963, 1964, 1965, 1967

21. —, UNESCO Statistical Yearbook, New York, 1963, 1964. 
22. - World Trade Annual, New York: Walker \& Co., 1963.

23. U. S. Department of Commerce, World Weather Reports 1941-50, Washington, D. C.: Government Printing Office, 1959.

24. L. D. H. Weld, "The Value of the Multiple Correlation Method in Determining Sales Potentials" Journal of Marketing, 3 (October 1939), 389-93.

25. H. R Wellman, 'The Distribution of Selling Effort Among Geographical Areas," Journal of Marketing, 3 (October 1939), 225-39.

26. V. Zamowitz, "An Appraisal of Short-term Economic Forecasts," Occasional Paper 104, National Bureau of Economic Research, New York, 1967 